\title{
Solar Light Harvesting Bimetallic Ag/Au Decorated Graphene Plasmonic System with Efficient Photoelectrochemical Performance for the Enhanced Water Reduction Process
}

Saikumar Manchala, ${ }^{\dagger, \downarrow}$ Lakshmana Reddy Nagappagari, ${ }^{\S}$ Shankar Muthukonda Venkatakrishnan, ${ }^{\S}$ and Vishnu Shanker*,†,

†Department of Chemistry, National Institute of Technology, Warangal, Telangana 506004, India

Centre for Advanced Materials, National Institute of Technology, Warangal, Telangana 506004, India

${ }^{\S}$ Nanocatalysis and Solar Fuels Research Laboratory, Department of Materials Science and Nanotechnology, Yogi Vemana University, Kadapa, Andhra Pradesh 516005, India

*Corresponding author Email: vishnu@ nitw.ac.in 


\section{Synthesis of Graphene Oxide:}

Graphene Oxide (GO) was prepared by using commercially available nano graphite powder through a modified Hummers method. ${ }^{1}$ In a brief procedure, nanographite powder (2 g) and $\mathrm{NaNO}_{3}(2 \mathrm{~g})$ were put into a $1000 \mathrm{~mL}$ R.B flask at $0{ }^{\circ} \mathrm{C}$ in an ice bath. Then $80 \mathrm{~mL}$ of $\mathrm{H}_{2} \mathrm{SO}_{4}$ was added slowly into the flask under stirring. Subsequently, $\mathrm{KMnO}_{4}(12 \mathrm{~g})$ was added in portions under ice bath and maintain the temperature below $10{ }^{\circ} \mathrm{C}$ for $2 \mathrm{~h}$. Afterward, the reaction solution was stirred for $2 \mathrm{~h}$ at $40{ }^{\circ} \mathrm{C}$. After completion of the reaction, $80 \mathrm{~mL}$ of water was added slowly into the solution under stirring for $1 \mathrm{~h}$ at $90{ }^{\circ} \mathrm{C}$. In the next step, the reaction solution was treated by the combination of $20 \mathrm{~mL}$ of $\mathrm{H}_{2} \mathrm{O}_{2}(30 \%)$ and $180 \mathrm{~mL}$ of water and stirred for $3 \mathrm{~h}$. Finally, the obtained solution was washed with $10 \% \mathrm{HCl}$ for several times and dried at $60{ }^{\circ} \mathrm{C}$ for $24 \mathrm{~h}$ in an oven.

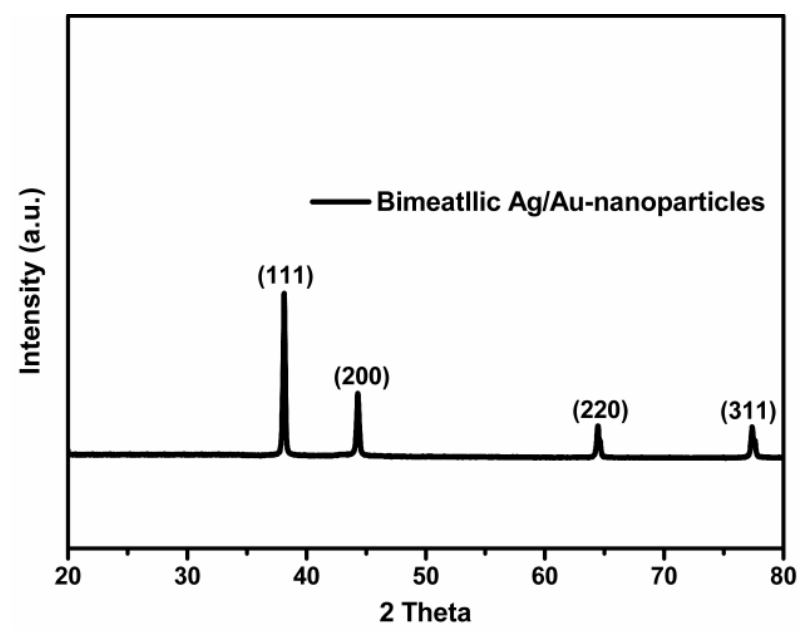

Figure S1. PXRD pattern of bimetallic Ag/Au nanoparticles.

\section{References}

(1) Goud, K. Y.; Hayat, A.; Catanante, G.; M., S.; Gobi, K. V.; Marty, J. L. An electrochemical aptasensor based on functionalized graphene oxide assisted electrocatalytic signal amplification of methylene blue for aflatoxin B1 detection. Electrochim. Acta 2017, 244, 96-103. 